\title{
Practicing the Intrapreneurship: a Case of Service-Sector Firms in Pakistan
}

\author{
Bushra Akbar Khan \\ Visiting Faculty at Middlesex Dubai \\ Zehra Roofi Budhwani \\ Assistant Professor at Bahria University Karachi Campus \\ Ahsan-ul-Haq Shaikh \\ Lecturer Institute of Business Administration in the University of Sindh, Jamshoro
}

\begin{abstract}
Purpose-Purpose of this study was to identify the level of existence of intrapreneurship among the service sectors organizations in Pakistan. The study entailed evaluation of awareness among the organizations' members regarding the concept of intrapreneurship, the determinants of intrapreneurship in these organizations and role of intrapreneurship in determining the profitability of those organizations. Existence and prospects of intrapreneurship among the Pakistani organizations were sought in the backdrop of increasing dynamism in business world that makes for them mandatory to become adaptive to new ideas, approaches and attitudes. Hence fast and cost effective innovation has become imperative for organizations that want to maintain their competitive advantage and leadership in the industry.

Methodology/Sample- The study sample comprised of 15 large organizations selected randomly from five sectors: banking, telecommunication, insurance, restaurants and healthcare; 2-3 firms randomly selected from each sector. 100 questionnaires were distributed among 6-8 employees from the selected organizations. Return on the questionnaires was $66 \%$.

Findings- Results of the study provided an overall view of various service sector organizations' intrapreneurial ability and outlook and explored the impact of intrapreneurship on organizations' overall performance and employee motivation.

Practical Implication- The study is believed to be useful in ascertaining adaptability of firms to foster and implement innovativeness in response to their changing external and internal environment and its impact on employee and organizational performance.
\end{abstract}

Keywords : Intrapreneurship, organization change, innovation, service organization

\section{Jel classification :}

\footnotetext{
* The material presented by the author does not necessarily portray the viewpoint of the editors and the management of the Institute of Business \& Technology (Biztek) or Middlesex Dubai, Bahria University Karachi Campus and University of Sindh, Jamshoro.

*Bushra Akbar Khan : bushra.akhan@yahoo.com

*Zehra Roofi Budhwani : zehraroofi@gmail.com

*Ahsan-ul-Haq Shaikh : ahsanshaikh3@yahoo.com

(C) JMSS is published by the Institute of Business and Technology (Biztek). Main Ibrahim Hydri Road, Korangi Creek, Karachi-75190, Pakistan.
} 


\section{PROBLEM BACKGROUND AND AIM OF STUDY}

In today's world, organizations are changing rapidly; hence it is very essential that managers welcome new ideas and approaches. Sustainable competitive advantage can only be achieved if organizations focus on innovation within their various departments. Globalization has forced many organizations to innovate and maintain their competitive advantage to survive in the cutthroat competitive market. Large organizations should replace corporate bureaucracy; top down command and control system with entrepreneurial empowerment else they will soon realize that they will cease to exist. Only flexible and adaptive organizations can survive in the international economy. Towards the end of the last century, a term intrapreneurship was introduced to represent such regime of autonomy, selfdirectedness and innovation in the organizations.

Intraprenuers are generally greatly self-driven, hands-on and pragmatic individuals who are feel at ease with inventive moves within the limits of an organization in quest of an innovative product or service (Investopedia 2013). Behavioral features of intrapreneurship comply initiative-taking, tendency and talent to "think outside the box", being adventuresome and leadership (ibid). From the corporate perspective, it is a way of management characterized by flexibility, innovation and risk taking for the aim of taking advantage of new opportunity through beating the rigmaroles of organizational bureaucracy. It refers to the individuals or groups in the organizations getting engaged in delving into the high-reward but high risk ideas and building substantial plans of action for their realization.

Being adaptive and innovative may be challenging and difficult especially as members of the organizations. However, the potential benefits are worth both the risk and the difficulties. Today's globalization of the business environment and its dynamism requires the corporate organizations stay adaptive to innovative ideas and creative approaches. Ross (1987), had corroborated this belief far earlier saying that the corporate organizations that appreciate and encourage the entrepreneurial fortitude among their work force, have the best of both worlds. This advisory holds true equally for the entire corporate sector organizations: manufacturing as well as service.

Initiation of intrapreneurial policies into an organization successfully requires introduction of holistic systems approach. Therefore organizations must move on to introduce, implement and prize intrapreneurship - in terms of its regularity and the rigor with which it is practiced. Hence it is imperative that entire workforce from senior management to the bottom level employees all should be engaged in nurturing the intrapreneurial fortitude (De Coning, 1992).

This study is being conducted in the backdrop of the complexity and instability of the Pakistani environment that seems badly in need of intrapreneural outlook. From the very initial stage of this research study, we were fully aware that the concept of intrapreneurship in Pakistan's service industries was a highly under researched field, hence very low expected awareness of intrapreneurship among the employees, management and the employers as a whole. However we were convinced that Pakistani organizations would display a high level of intrapreneurial behavior due to the country's energetic and progressively tumultuous social, political and economic atmosphere, especially the following factors have led companies to incorporate intrapreneurship, knowingly or unknowingly, within their organizations.

1. Traditional organizations within Pakistan are fast being replaced with new concepts of teamwork, global market and customer driven focus.

2. People are being hired based on interpersonal skills, problem solving abilities, computer literacy, innovative and proactive orientation.

3. Advancement in information technology has compelled employees to learn new technical skills and become multi-skilled. 


\subsection{Research Questions}

i. What is the level of awareness relating to the concept of intrapreneurship among the employees in the service sector organizations in Pakistan?

ii. To what extent the service sector organizations of Pakistan do have policies and support systems necessary for encouraging intrapreneurship?

iii. What is the impact of external environmental on the intrapreneurial character of service sector organizations of Pakistan?

iv. In which functional areas of service sector organizations of Pakistan mostly intrapreneurship is being practiced?

v. What is the role of intrapreneurship in improving profitability and growth of service sector organizations of Pakistan?

\section{LITERATURE REVIEW}

American Hertigage Dictionary of The English Lanugage, 3rd Edition defines intrapreneur as "a person within a large corporation who takes direct responsibility for turning an idea into a profitable finished product through assertive risk-taking and innovation. The term intrapreneurship is derivative of a amalgamation of "intra" and "entrepreneurship - describing the practice of entrepreneurship within organizations. Today, this term has become a synonym for organizations that foster innovative culture to avail opportunities, implement actions and produce new innovative products and services.

This term is attributed to Gifford Pinchot (1985) who used it in his book, "Intrapreneuring: Why You Don't Have to Leave the Corporation to Become an Entrepreneur." He gave the term intrapreneur regular meanings; "a person who concentrates on creativity, originality and innovation and who transforms a vision or an idea into a gainful undertaking, by operating within the organizational environs." Finally, it was added to American Heritage Dictionary of the English Language (3rd Ed) in 1992.

In practice, the term intrapreneur means an individual who has entrepreneurial skills and uses them within an organization innovatively (Pinchot 1985). Authors, like Chisholm (1987); McGinnis and Verney (1987); Kuratko et al. (1990); and Carrier (1996), have given more elaborated descriptions of this term. They view intrapreneurship as "a way of exciting innovation within the company using the creative talent of the workforce by providing them needed wherewithal and freedom to act within the organization" (cited in Kolveried \& Amo, 2002).

Put more comprehensively, intrapreneurship is entrepreneurship within an existing organization (Stanworth \& Curran 1999). Also termed as corporate venturing, it refers to the application of entrepreneurial principles within existing organizations and is cited as particularly important in the development of innovative marketing strategies at the firm level; (Timmons \& Spinelli 2004). Put in another way, it may be defined as a process whereby the employees within the organizations track opportunities improvising with the resources currently available to them (Stevenson \& Jarillo, 1990). It involves looking for creative answers to problems the organizations are facing, like designing new products, development of new approaches and policies, and designing and redesigning organizational structures and systems etc.

The concept has its roots into the beliefs that successful incorporation of swift and efficient innovation is the principal basis of durable competitive advantage in the contemporary times, leaving the organizations with no option but to innovate well or cease to exist. Bornman (1992) agrees with the observation and suggests that introduction of the concept of intrapreneurship will allow the managers to foresee the new developments likely be effecting their organizations, and thus, incorporate these developments into their strategic plans for maintaining the competitive advantage. Robbins (1997) expresses similar beliefs 
saying that the successful organization of tomorrow must cultivate culture of innovation or become ready for extinction. He further says that only those organizations will be successful which maintain their flexibility, persistently enhance quality of their product, and beat their competitors with a relentless course of pioneering products and services.

Research in the field of intrapreneurship, however, has been somewhat limited especially in the service sector of Pakistan where only few studies have been conducted to analyze the adaptability and the potential success of organizations that claim to encourage intrapreneurship.

\subsection{Difference between Entreprenureship and Intrapreneurship}

Thornberry (2003) says that entrepreneurship and intrapreneurship have some commonalities with the 'start up' entrepreneurship, however, they differ from each other as well. Entrepreneurship, in general, is considered as the 'primary act or catalyst underpinning innovation' and usually describing radical change mechanisms such as spin-out, start-up or new company ventures, all of which tend to happen outside a conventional organization. In contrast, intrapreneurship involves using entrepreneurial behaviour within an organisation and for its implementation a different but overlapping set of skills is required (Thornberry, 2003). So one can say that intrapreneurs are the "dreamers who do" (Stevenson \& Jarillo, 1990) - unlike majority of the people who are either dreamers or doers. So intrapreneurs are the people who implement as well what do they dream and imagine about. This distinguishes them from an inventor who only imagines 5 to 10 years down the road (Thornberry, 2003). In other words, inventors develop new products whereas Intrapreneurs turn up with new methods and practices that steer that product or services to the market.

\subsection{Role of Employees in Intrapreneurship}

Main feature of the literature on this subject is its emphasis on the employee contribution towards promotion of this school of thought. Intrapreneurship particularly involves incorporating workforce inputs that could lead to financial benefits, while at the same time endeavoring to institute reward systems that productively affect innovation and motivation. (Cooper, 1985; Gupta, 1995; Jones \& Butler, 1992). Drucker (1998) supported this view proposing two sets of opportunities; a set of four areas offering opportunities within the organization while a set of three areas offering opportunities outside the organization. He was of the view that creative and innovative employees can make use of these opportunities. Drucker's (ibid) areas of opportunity within a company or industry are:

- Unanticipated events.

- Incongruities.

- Process requirements.

- Industry and market changes.

While the vicinity of opportunities present outside an organization are (ibid):

- Demographic change.

- Changes in perception.

- New knowledge

To give a climax to the school of conviction about central role of the employees in intrapreneurship and the need for organizational support and reward in that regard, Pinchot (1999) suggested a set of skills, abilities and behaviours necessary to be developed among the employees for promotion of organizational intrapreneurism.

- Social knowledge to make innovations significant

- Prior intrepreneurial or entrepreneurial understanding 
- Inventiveness

- To identify prospects that others could not identify

- To interact with other organizational experts and customers

- To correspond effectively across the technical boundaries

- Self-efficacy in initiating or leading the organizational change processes

- Risk orientation

- Forbearance against uncertainty and ambiguity

- High need for achievement

- Understanding the organizational power and politics

These ten steps eventually focus upon making the organizations supportive, tolerant and flexible. During the early 1990s, most of the big companies had a "command-andcontrol" structure where the chain of command was from the top to the bottom. This structure worked well when the rate of technological change was slow. But as the economy changed, companies discovered they needed more flexibility. Therefore, the divisions of the "command-and-control" structure were eliminated and multi-disciplinary teams were introduced.

\subsection{Characteristics of an Intrapreneurial Organizations}

Intrapreneurial organizations are those that avoid corporate bureaucracy in order to flourish innovation and remain creative and hence competitive. This leads to greater job satisfaction and productivity of employees. Pinchot (1999) has developed eight characteristics of the intrapreneurial organizations:

1. Building teams - intrapreneuring is not an all alone pursuit.

2. Sharing recognition broadly among the team members.

3. Encouraging the members to share their ideas.

4. Training the members to promise less and deliver more - publicity triggers the corporate immune system.

5. Developing the culture of going beyond one's job description - to let the employees do any job that needs them make their dream work.

6. Promoting culture of tolerance for mistakes for the sake of higher learning.

7. Giving preference to the best interests of the company.

8. Promoting loyalty among the members to their goals while remaining realistic about how to achieve them.

Earnes \& Young, (2013) are of the view that intrapreneurship cannot thrive without two factors being taken care of:

1. Sponsorship by the top management

2. Job security - individuals engaged in intrapreneurial adventures will not lose their job if the new idea fails. Nor will they be punished in any way.

Intrapreneurship demands a flexible and swift organizational structure and function that encourages ideating and accommodates failure. The organizations, especially the larger ones, that are made of rigid, hierarchical institutional structures have tendency of smothering the intrapreneurial spirit of the individuals and the groups.

\subsection{Barriers to Intrapreneurship}

There are some barriers in the way of creating intrapreneurship in any organization and cultivate such an environment which is conducive to intrapreneurship. Large and growing organizations need to take advantage of synergies, economies of scale and shared risk taking for its success (Thornberry, 2003). Therefore intrapreneurship is difficult to implement in large bureaucratic organizations where cost controls, policies and guidelines are rigid and prevalent. Most firms drive in defined boundaries with defined framework and risk 
parameters (Timmons \& Spinelli 2004), and there is scarcity of people who are brave enough to take on the intrapreneurial role and break the boundary. Therefore organizations can hire and train them to become future intrapreneurs.

Eesley \& Longenecker (2006) very correctly describe barriers to intrapreneurship saying these barriers are useful to know about before discussing gateways to improving organizational intrapreneurship:

- When organizations punish risk taking and the mistakes associated with new ideas or innovation, intrapreneurship is stifled and will disappear with time.

- When organizations do not listen to their members' input about how to make things better and there is no follow up on improvement ideas, they discourage the very things needed for organizational improvement to flourish.

- When an organization fails to sanction, promote, and encourage risk taking, empowerment, and improvement actions, it greatly reduces the likelihood of creating an environment of better performance.

- Organizations that are replete with unhealthy political activity, infighting, and uncooperative organizational members have a very difficult time bringing out the best in people to create better business performance.

- When organizations are characterized by poor communication and structural silos that prevent the flow of useful information, intrapreneurship suffers greatly.

- When organizations do not encourage and empower the employees to look for ways to improve an organization's performance; there is unclear organizational direction, priorities, and objectives; and there is lack of top management support in risk taking and improvement initiatives.

- Finally, when risk taking and improvement activities are not rewarded and when employees have inadequate resources and time, intrapreneurship will either die never gain enough momentum to become a competitive advantage.

\section{RESEARCH METHOD}

Questionnaire was used as primary empirical data collection methods in this study. Questionnaire was used to measure:

i. Awareness and attitude of employees and management towards intrapreneurship

ii. Intrapreneurship friendly policies, reward and support systems of the organizations

iii. Environmental changes causing intrapreneurship among the organizations.

iv. Functional area wherein the organizations are mostly practicing intrapreneurship

v. Impact of intrapreneurship on organizational performance and profitability.

First pilot questionnaire was developed that was tested in a small group of the target respondents and final draft was achieved through the feedback of the pilot questionnaire. Percentage scores were incorporated in the analysis for each service sector. All the independent variables were studied through statistical techniques and their relationship to the dependent variable i.e. organizational and employee motivation towards intrapreneurship was discussed.

\subsection{Sampling}

For the purpose of this study, 14 large service organizations were selected randomly from five predetermined strata namely: Banking, Telecommunication, Insurance, Restaurants and Healthcare (hospitals). Sample consisted of 3 organizations from Telecommunication, 3 from banking industry, 2 from restaurants, 3 from healthcare and 3 from insurance sector. Then 6 to 8 employees were selected from each organization on convenience basis to serve with the questionnaire. The selection criteria comprised working at a management level in one of the chosen organizations. In this way 100 employees in total were served with the questionnaire out of which 66 responded ( $66 \%$ response). 


\section{RESULTS}

\subsection{Level of awareness of intrapreneurship among employees}

The percentage scores did not show a very strong awareness of intrapreneurship amongst the organizational employees. This is reflected by less innovation incorporated in organizations, rigid systems and guidelines and greater fear of failure amongst the employees. In the telecom industry, 54\% respondents said that they look 'often' for new ideas as compared to $50 \%$ employees of banking and insurance industries and $40 \%$ respondents of the restaurant sector. A slightly different trend was followed in healthcare as comparatively meager $27 \%$ employees 'always' and 'often' look for new ideas.

Figure 1:

Level of Awareness among employees regarding intrapreneurship

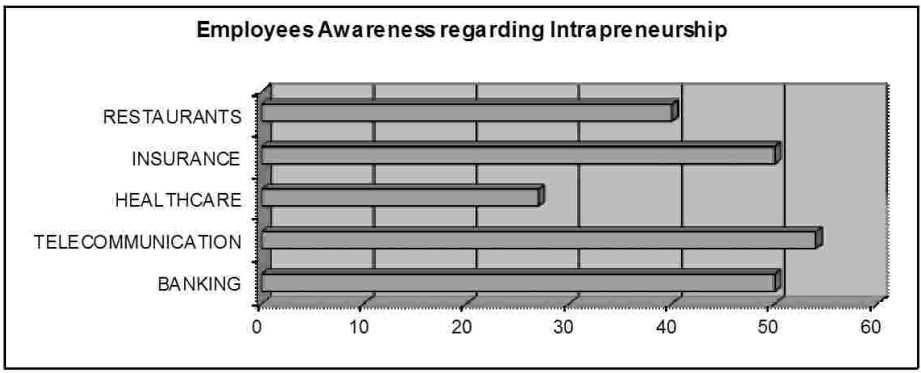

\subsection{Presence of intrapreneurial programs in the organizations}

Almost all (93\%) of the respondents from the banking sector agreed that intrapreneurial programs were being introduced and they were provided with opportunities to be a part of those programs. In the telecom industry a huge majority of $84.6 \%$ agreed to the presence and awareness of intrapreneurship in their organizations. Healthcare sector showed $73 \%$ employees believing in the presence of enough opportunities of creativity and innovation. Almost similar pattern was observed in the restaurant sector with a majority of $80 \%$ respondents agreeing to being provided with innovative culture in their organizations. The results from the insurance industry showed a different trend, however, with only $28.5 \%$ agreeing to the presence of intrapreneurial program in their organizations.

Figure 2:

Intrapreneurship policies and programs into organizations

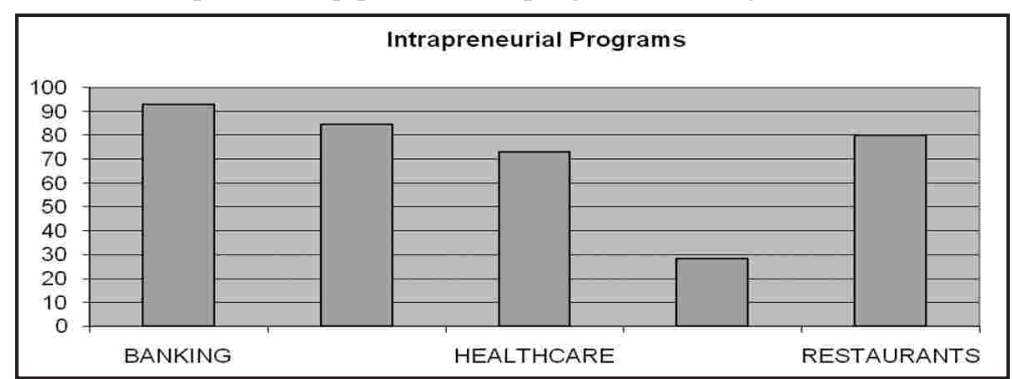

\subsection{Impact of external environment over organizational intrapreneurship}

The results showed a very strong impact of external environment on the organizations' quest for intrapreneurship. For instance, $86 \%$ respondents of banking industry and $100 \%$ 
respondents of telecom sector believed that they have been involved in introducing 'few' to 'many' service innovations in the last two years due to environmental changes.. The insurance sector showed a quick response to environment dynamics with all $100 \%$ respondents claiming to be involved in 'few' to 'many' innovative product/services. In the restaurants there was a slightly different picture with $50 \%$ each of the respondents being involved in launching 'few' to 'many' and 'none' to 'few" innovative product/services. However respondents from the health sector again had a different opinion with only $27 \%$ believed to have been introduced to new products in the last two years hence showing a very slow response to external environment volatility.

Figure 3:

Effect of environmental changes on the intrapreneurial character of the organizations

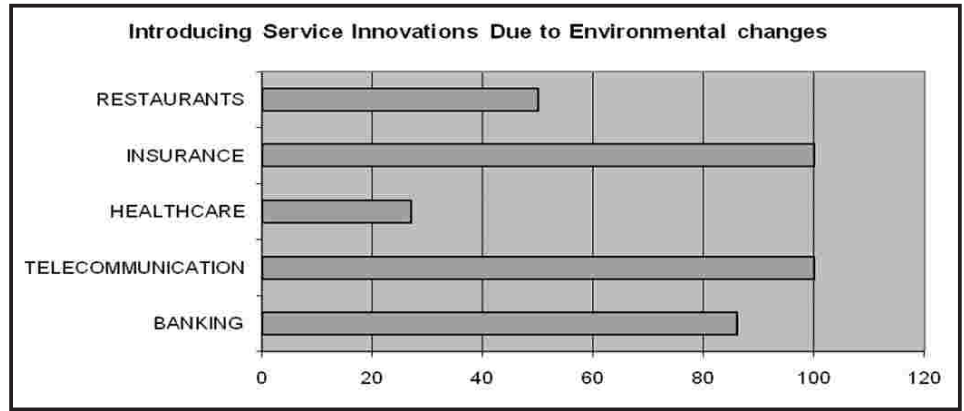

\subsection{Functional area wherein intrapreneurship is being practiced}

A majority of $57 \%$ respondents from the banking industry identified marketing as a primary functional area fostering intrapreneurship in organizations. It was followed by $R \& D(21.4 \%)$ and finance $(14 \%)$. In the telecom industry again marketing was identified as a primary function by $46 \%$ followed by $R \& D(38.5 \%)$. Overwhelming majority $(86 \%)$ of the insurance sector respondents also pointed marketing department with dominating intrapreneurship outlook. The restaurant sector also identified marketing $(40 \%)$ as a primary functional area for incorporating intrapreneurship. It was followed by Quality Control $(30 \%)$ and Public Relations (30\%)

Figure 4:

Functional areas with intrapreneurship practice

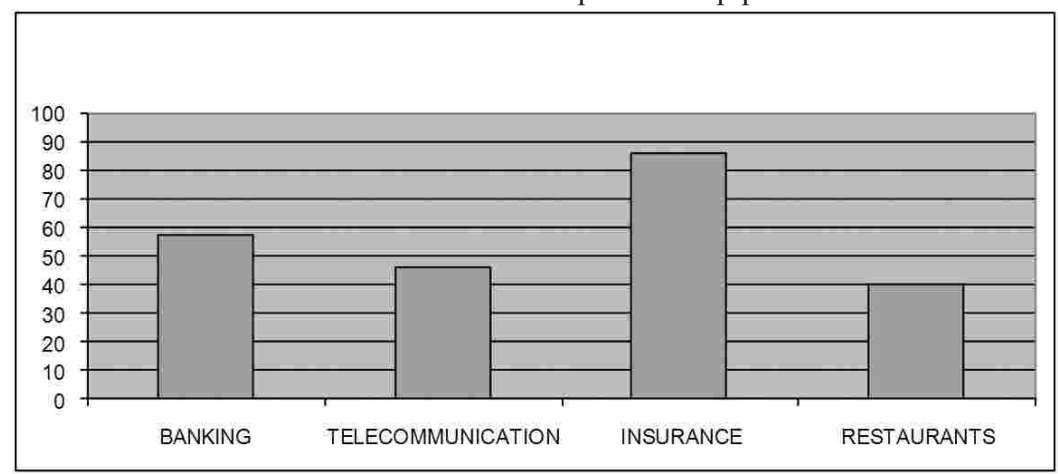

4.5 Impact of intrapreneurship on organizational performance

$100 \%$ respondents in banking and restaurant sectors believed that the intrapreneurial 
activities in their organizations had a significant impact on their sales, profits and return on investment. Similar views were shared by the telecom sector respondents where $97 \%$ agreed to a significant impact of intrapreneurship on organizational performance (sales, profit, and return on investment). In the Insurance sector a majority believed in a significant improvement due to incorporation of innovativeness (sales $57 \%$, profits $78 \%$, and return on investment $100 \%$ ). However the opinion of the employees in the healthcare sector was slightly different with a majority of $80 \%$ believing that the impact of intrapreneurship was moderate on their organizations' sales, profit and return on investment.

Table 1:

Impact on Organizational Performance

\begin{tabular}{|l|c|c|c|c|c|c|}
\hline Service Sector & \multicolumn{2}{|c|}{ Sales\% } & \multicolumn{2}{c|}{ Profit\% } & \multicolumn{2}{l|}{$\begin{array}{l}\text { Return on } \\
\text { Investment \% }\end{array}$} \\
\hline & Moderate & Significant & Moderate & Significant & Moderate & Significant \\
\hline Banking & & 100 & & 100 & & 100 \\
\hline Telecommunication & 3 & 97 & 3 & 97 & 3 & 97 \\
\hline Healthcare & 80 & 20 & 80 & 20 & 80 & 20 \\
\hline Insurance & 43 & 57 & 22 & 78 & & 100 \\
\hline Restaurants & & 100 & & 100 & & 100 \\
\hline
\end{tabular}

Figure 5:

Impact of intrapreneurship on sales

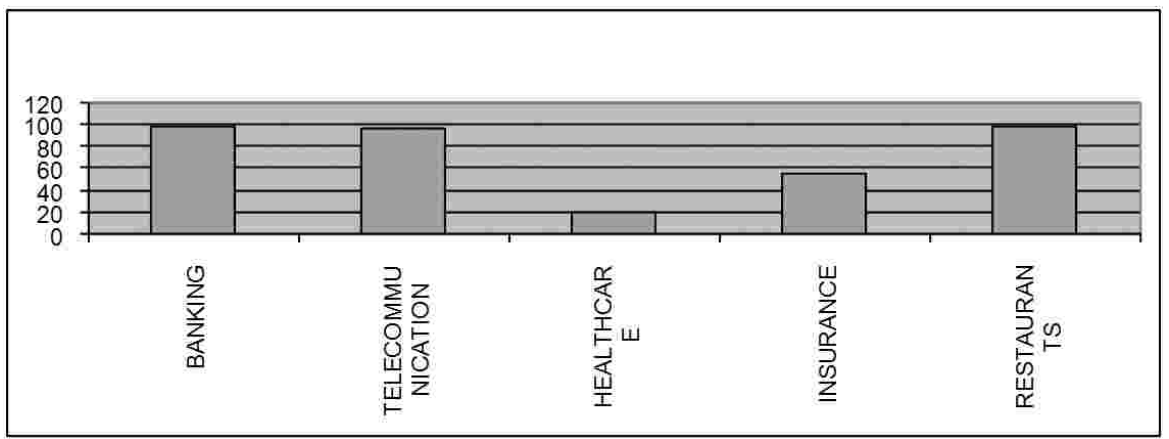

Figure 6:

Impact of intrapreneurship on organizations' profits

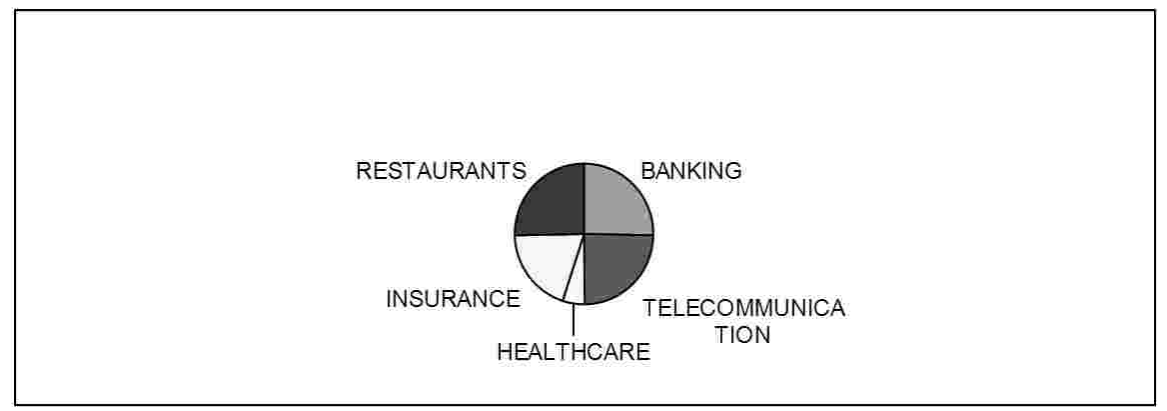


Figure 7:

Impact of intrapreneurship over ROI

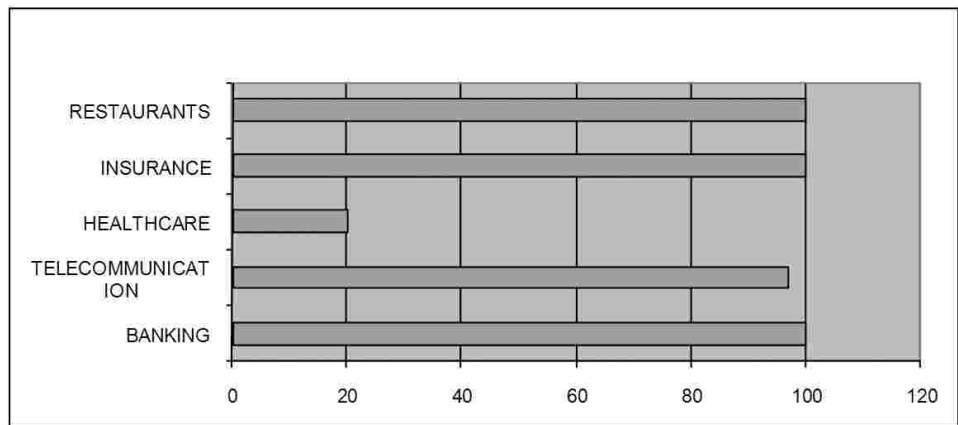

\section{CONCLUSION}

Almost all of the respondents from the banking sector agreed that intrapreneurial programs were being introduced and they were provided with opportunities to be a part of them. In the telecom industry, an overwhelming majority agreed to the presence and awareness of intrapreneurship in their organizations. Healthcare sector showed three fourth employees believed in the presence of enough opportunities of creativity and innovation. Almost similar pattern was observed in the restaurant sector where a dominating majority of respondents agreed with having an innovative culture in their organizations. The results from the insurance industry showed a different trend, however, with only one fourth respondents agreeing to the presence of intrapreneurial program.

Due to the highly volatile nature of the Pakistani external environment, it was imperative to study the impact on organizations intrapreneurial culture. It was observed that the healthcare and restaurants were lagging behind in incorporating intrapreneurship as a strategy to tackle the dynamics of environment. Whereas the other sectors studied showed a high focus on fostering an innovative culture to gain and retain competitive advantage in today's turbulent environment. The primary functional area responsible for encouraging an innovative culture was identified mostly the Marketing especially in the banking sector, telecom, insurance, and restaurants. Other important functional areas where intrapreneurship was observed being practiced were Research and Development, Public Relations, and Quality Control. However one third respondents in health care sector believed that in their organizations Personnel department is more innovative.

Almost all the respondents in the study believed that intrapreneurial activities in an organization resulted in boosting employees' motivation level and. However there was a completely different opinion shared by the respondents from the healthcare wherein only one fourth respondents found any sort of rewards or recognition from their organizations to boost their morale.

An overwhelming majority of the respondents believed that the intrapreneurial activities in their organization had a significant impact on their sales, profits and return on investment. The insurance sector witnessed a slightly different response for experiencing a significant improvement due to incorporation of innovativeness. However a majority of healthcare respondents believed that the impact of intrapreneurship was moderate on their organizations sales, profit and return on investment.

Since the sample size of the current research study was comparatively small and limited due to time and geographical constraints, further research with larger sample can be undertaken on the same lines. It was also realized during the study that a separate study should be undertaken to identify and analyze departmental intrapreneurial qualities and 
their overall impact on organizations and employee performance. In other words it is productive to understand difference between departmental intrapreneurship and organizational intrapreneurship. This study concluded that there is strong possibility of existence of departments within the organization with uneven intrapreneurial capacity and outlook. For example the marketing department in all organizations was more innovative than the finance department.

\section{REFERENCES}

1. Baumol, W. J. (1968)..Entrepreeurship in economic theory. American Economic Review, 58,64-65

2. Bornman, L. (1992) Managing for learning, People Dynamics, 10,19.

3. Burgelman, R. A. (1983): "A Model of the Interaction of Strategic Behavior, Corporate Context, and the Concept of Strategy", Academy of Management Review, 8, 1, 6171.

4. Carrier, Camille. "Intrapreneurship in Small Businesses: An Exploratory Study." Entrepreneurship: Theory and Practice. Fall 1996.

5. Cooper,A. C. (1985). The role of incubator organizations in the founding of growthoriented firms. Journal of Business Venturing,1,75-86.

6. De Coning, T. (1992) Intrapreneurship-Another Bright Idea? People Dynamics, 11.10.

7. Donald W. Irwin (1988). "Fostering Intrapreneurship: The New Competitive Edge." Journal of Business Strategy. May-June.

8. Drucker, P. F. (1984). Our Entrepreneurial Economy. Harvard Business Review, 1, 5964.

9. Earnes \& Young (2013) http://www.ey.com/GL/en/Services/Strategic-GrowthMarkets/Igniting-innovation)

10. Eesley, D. T. \& Longenecker, C. O. (2006) Gateways to Intrapreneurship, Industrial Management Journal, May-June

11. Gupta, U, (1995, August 7). Intrapreneurs from the inside out. Information Week, 12 14.

12. Investopedia (2013) http://www.investopedia.com/terms/i/intrapreneurship.aspJones, (accessed on March 10,2013)

13. G. R. \& Buttler, J. E (1992). Managing: Internal corporate entrepreneurship: An agency theory perspective. Journal of Management, 18(4),733-749

14. Miller, D. \& Friesen, P.H. (1983). Innovation in Conservative and Entrepreneurial Firms: Two Models of Strategic Monument. Strategic Management Journal, 3.1.

15. HAS YOUR ORGANIZATION MADE THIS UNFORGIVABLE MISTAKE TOO? http://www.differworld.com/for-your-organisation/index.php

16. Frank, S. \& Kim, S. (2008) "How can you pass on business? Denver Business Journal - June

17. Pinchot, G. (1985) "Intrapreneuring": Why You Don't Have to Leave the Corporation to Become an Entrepreneur." Carrier, Camille. "Intrapreneurship in Large Firms and SMEs: A Comparative Study." International Small Business Journal. April-June 1994.

18. Pinchot, G (1999). American Heritage Dictionary of The English Language, $3^{\text {rd }}$ Edition Ten Steps to an Entrepreneurial Organization Rule, Erik G., and

19. Pinchot, G, and Ron Pellman (1999). Intrapreneuring in Action. A Handbook for Business Innovation.

20. Pinchot, G. (2000). Intrapreneuring: why you don't have to leave the corporation to become an entrepreneur. San Fransico: Berrett-Koehler.

21. Robbins, S. P. (1997). Organizational Behavior. New Jersey: Prentice Hall International.

22. Ross, J. (1987) Corporations and Entrepreneurs. Business Horizons, $30,4$. 